\title{
Molecular Characterization of Norovirus GII Strains Identified in Albania
}

\author{
Domenica Donia, ${ }^{1 *}$ Fabian Cenko, ${ }^{2}$ and Maurizio Divizia ${ }^{1}$ \\ ${ }^{1}$ Department of Public Health, University of Tor Vergata, Rome, Italy \\ ${ }^{2}$ Professional Development System Project, Ministry of Health, Tirane, Albania
}

Noroviruses (NoVs) are considered as the leading cause of diarrheal diseases in all groups of age. In the last decade the number of NoV outbreaks worldwide is increasing. Data published by the systems of NoV surveillance show the Gll.4 strain as the human predominant genotype circulating worldwide and new genetic variants of Gll.4 were associated with epidemic events. In Albania the economy transformation has damaged significantly the environment and a large circulation of enteric viruses was reported in the past with the presence of NoV among the genotyped strains. This study aimed to characterize, by molecular analysis, the NoV GIl strains detected in Albania during two time periods: in 2010 from the outbreak occurred in Ballsh and in 2002-2003 from sporadic cases of diarrhoea. A total of 21 Nov Gll strains were characterized. The NoV Gll.4 was genotyped more frequently and it was related closely to the pandemic variants recorded in GenBank. During 2002-2003, six NoV GIl recombinant strains have been characterized. J. Med. Virol. 85:731-736, 2013. ๑ 2013 Wiley Periodicals, Inc.

KEY WORDS: genotyping; molecular characterization; polymerase chain reaction; viruses

\section{INTRODUCTION}

Noroviruses (NoVs) are considered as the leading cause of diarrheal diseases in all groups of age; it is estimated that NoVs cause $50 \%$ of all worldwide outbreaks of viral gastroenteritis [Patel et al., 2008]. The infection may be occurring through contaminated water or food and person-to-person contacts [Hedberg and Osterholm, 1993; Koopmans et al., 2002; Marshall and Bruggink, 2011].

Genetically diverse, NoVs are classified into five distinct genogroups $(\mathrm{G})$ and further subdivided into genotypes. Genogroup I (GI) and genogroup II (GII) are recognized as the predominant cause of outbreaks in humans. The NoV genome, a positive sense singlestranded RNA, is organized into three open-reading frames (ORFs). ORF1 encodes for the non-structural proteins including a RNA-dependent RNA polymerase (RdRp). The viral capsid protein (VP1) is encoded by ORF2 gene and regulates the virus antigenicity, hostspecificity, and environmental stability [Siebenga et al., 2010]; the minor structural protein is encoded by ORF3 with unknown function [Belliot et al., 2003]. In the last decade the number of reports about $\mathrm{NoV}$ outbreaks increased worldwide. Data published by the systems of NoV surveillance (NoroNet; CaliciNet; ViroNet) describe the GII.4 strain as the genotype predominant in human circulating in the world and new GII.4 genetic variants were identified associated with epidemic events [Bull et al., 2006; Tu et al., 2008; Siebenga et al., 2009; Eden et al., 2010]. The literature does not report data about NoV outbreaks in Albania. A large circulation of enteric viruses has been reported in this country during 2002-2003 by Arrivi et al. [2007] with $12.9 \%$ of NoVs presence among recognized viral gastroenteritis (11 cases have been GII strains related). The first described outbreak of NoV occurred in Ballsh district during the spring 2010 [Donia et al., 2011]; the RT-PCR identified a single NoV strain genotyped as GII.4. The aims of this study were: a molecular characterization of the NoV GII strains detected in Albania during two different time periods (the strains identified during the outbreak occurred in 2010 and the strains identified from sporadic cases of diarrhoea during 2002-2003) and the comparison of these, by phylogenetic analysis, with the GII strains and GII.4 sub-genotypes circulating in the European epidemiological scenery, at the time of detection, basing on the data recorded in the main Surveillance Networks for NoV.

*Correspondence to: Domenica Donia, Department of Public Health, University of Tor Vergata, Via Montpellier 1, Rome 00133, Italy. E-mail: donia@med.uniroma2.it

Accepted 6 November 2012

DOI 10.1002/jmv.23488

Published online 30 January 2013 in Wiley Online Library

(wileyonlinelibrary.com). 


\section{MATERIALS AND METHODS}

\section{Specimen Collection}

Stool samples were collected from patients with gastroenteritis [Arrivi et al., 2007] admitted to the Pediatric ward and to the Emergency pediatric Unit of the Tirane University Hospital, during 2002-2003 and from the Ballsh outbreak, which occurred in 2010 as reported previously [Donia et al., 2011]. All the samples were transferred to Tor Vergata University (Rome, Italy) employing the cold chain requirement and stored immediately at $-80^{\circ} \mathrm{C}$. Screening for $\mathrm{NoV}$ presence was performed by ELISA in the hospital in Albania and by RT-PCR method in Italy.

\section{RNA Extraction}

Viral RNA was extracted using Trizol LS reagent (Invitrogen, Life Technology, Italy), according to the manufacturer's instructions, from faecal specimens prepared as described previously [Donia et al., 2011].

\section{RT-PCR Amplification}

Several portions of ORF1 and ORF2 regions of the NoV genome were amplified by RT-PCR. In 20022003, the detection of NoV from stool samples was obtained using the method proposed by Häfliger et al. [1997] which amplifies a part of ORF1 genome (region A). Subsequently an additional test was carried out from positive stool samples for NoV GII, stored at $-80^{\circ} \mathrm{C}$, using the protocol applied for the diagnosis of the Ballsh outbreak [Donia et al., 2011]. RNA was reverse transcribed to complementary DNA (cDNA) with 50 pmol of random hexamers (Roche, Milan, Italy) in $20 \mu \mathrm{l}$ of the reaction mixture containing $4 \mathrm{U}$ of AMV (avian myeloblastosis virus) reverse transcriptase (Promega, Milan, Italy). After incubation at $42^{\circ} \mathrm{C}$ for $1 \mathrm{hr}, 5 \mu \mathrm{l}$ of cDNA were amplified in a semi-nested PCR targeting a $344 \mathrm{bp}$ size of the ORF1/ORF2 genome (region $\mathrm{C}$ ). The first round of PCR was carried out using COG2F and G2SKR primers, the second round of PCR using primers G2SKF and G2SKR [Kojima et al., 2002; Kageyama et al., 2003]. The region D of VP1 gene was amplified in a single round of PCR according to Vinjé et al. [2004]. In addition, all cDNAs (from samples collected during 2002-2003 and 2010) were tested by a semi-nested PCR amplifying a $250 \mathrm{bp}$ size of the ORF1 gene (region A) using a primers set designed previously in house and tested in a qRT-PCR applied in environmental analyses (data not shown): IIF 5'-CCAGATAGTTGCAGAAGACC-3' (corresponding to nucleotides $4,387-4,406$ in the Hawaii virus-U07611), IIR5'-CGTATTCCTTGAGCTTTGCT-3' (4,667-4,648 nt), IIR ${ }_{2} 5^{\prime}$-TGGGTTTAAGTTTATATCTG-3' $(4,636-4,617 \mathrm{nt})$.

\section{Sequence Analysis of Amplification Products}

The amplified products were visualized under UV lamp after electrophoresis in $2 \%$ agarose gel stained with ethidium bromide. The positive fragments were purified using the Qiaquick kit (Qiagen, Milan, Italy), according to the manufacturer's instructions, and sequenced by the Big Dye Terminator Cycle Sequencing Ready Reaction version 2.0 (Perkin-Elmer, Rome, Italy). Forward primers were used to sequencing amplicons of ORF1 and ORF2 regions and the reverse primer to sequencing amplicons of the region D (VP1 gene). Genotyping was determined using the tool of NoV genotyping at http://www.rivm.nl web site (National Institute of Public Health and the Environment, the Netherlands); whereas, the most closely related homology of the sequences has been established by BLAST search program (http://www.ncbi.nlm. NCBI.gov/BLAST). Reference strains for phylogenetic analysis were selected from the RIVM and NCBI. Multiple sequences were aligned with reference strains using MULTALIN software [Corpet, 1988], after manual adjustment of the sequences, and phylogenetic analyses were conducted using MEGA version 5.05 [Tamura et al., 2011]. Phylogenetic trees were constructed by the neighbor-joining method and the reliability was determined by bootstrap re-sampling of 1,000 replicates. Only nodes with a bootstrap value $>60 \%$ are labeled.

\section{Nucleotide Sequence Accession Numbers}

The nucleotide sequences of NoV strains analyzed in this study were deposited in GenBank under accession numbers JQ861246-JQ861250.

\section{RESULTS}

A total of 21 Nov GII strains were examined for molecular analysis: 11 detected from patients with gastroenteritis collected during 2002-2003 and 10 from the outbreak occurred in Ballsh during the spring 2010. Overall, 42 sequences were obtained from the different regions amplified and the strains identified are listed in Table I.

\section{Characterization of the NoV GII Strains Detected in 2002-2003}

The NoV GII positive strains identified from patients of sporadic gastroenteritis (2002-2003) were analyzed by sequencing. Eleven new sequences were obtained in addition to the previous results (11 sequences with SRII-2 primer) after the amplification tests carried out with the RT-PCR protocols targeting the regions mentioned above. In particular, three sequences for ORF1 (IIF primer), four sequences for ORF2 (G2SKF primer), and four sequences for VP1region $\mathrm{D}$ (Cap $\mathrm{C}$ primer) were obtained. The genotyping of NoVs, obtained using NCBI data bank (SRII.2 primer), has classified four strains as GII.4, one strain as GII.2 while six strains have been assigned at GII genogroup but not genotyped clearly (Table I). Subsequently, the RIVM website has confirmed one strain genotyped as GII.2, five strains genotyped as GII.4, 
TABLE I. Identification of Norovirus GII Strains Detected in Albania

\begin{tabular}{|c|c|c|c|c|c|}
\hline $\begin{array}{l}\text { Sample } \\
\text { identification/ } \\
\text { year }\end{array}$ & $\begin{array}{r}\text { SR } \\
\text { [Häfli } \\
\text { ORF-1 }\end{array}$ & $\begin{array}{l}\text { II-2 primer } \\
\text { rer et al., 1997] } \\
\text { region A (RdRp) }\end{array}$ & $\begin{array}{c}\text { IIF primer } \\
\text { (this study) } \\
\text { ORF-1 region A (RdRp) }\end{array}$ & $\begin{array}{c}\text { G2SKF primer } \\
\text { [Kojima et al., 2002] } \\
\text { ORF-2 region C }\end{array}$ & $\begin{array}{c}\text { Cap C primer } \\
\text { [Vinjé et al., 2004] } \\
\text { ORF-2, VP1 region D }\end{array}$ \\
\hline $1 / 2002$ & $\begin{array}{l}\text { (RIVM) } \\
\text { (NCBI) }\end{array}$ & $\begin{array}{l}\text { GII.2/DQ456824 } \\
\text { GII.2/AB279555 }\end{array}$ & Negative & Negative & Negative \\
\hline $11 / 2002$ & $\begin{array}{l}\text { (RIVM) } \\
\text { (NCBI) }\end{array}$ & $\begin{array}{l}\text { GII.h/AB089882 } \\
\text { GII/DQ026451 }\end{array}$ & Negative & $\begin{array}{l}\text { GII.2/AY134748 } \\
\text { GII.2/AB281082 }\end{array}$ & $\begin{array}{l}\text { GII.3/EU187437 } \\
\text { GII.3/HM072044 }\end{array}$ \\
\hline $14 / 2002$ & $\begin{array}{l}\text { (RIVM) } \\
\text { (NCBI) }\end{array}$ & $\begin{array}{l}\text { GII.n/GQ856469 } \\
\text { GII/AB112321 }\end{array}$ & $\begin{array}{l}\text { Bristol/X76716 } \\
\text { Lordsdale/X86557 }\end{array}$ & $\begin{array}{l}\text { GII.3/EU187437 } \\
\text { GII/AB112321 }\end{array}$ & $\begin{array}{l}\text { GII.2/AY134748 } \\
\text { GII.2/AB281081 }\end{array}$ \\
\hline $72 / 2002$ & $\begin{array}{l}\text { (RIVM) } \\
\text { (NCBI) }\end{array}$ & $\begin{array}{l}\text { GII.4/DQ078814 } \\
\text { GII.4/EU310927 }\end{array}$ & Negative & Negative & Negative \\
\hline $96 / 2002$ & $\begin{array}{l}\text { (RIVM) } \\
\text { (NCBI) }\end{array}$ & $\begin{array}{l}\text { GII.n/GQ856469 } \\
\text { GII/AB112321 }\end{array}$ & Negative & NP & NP \\
\hline $106 / 2002$ & $\begin{array}{l}\text { (RIVM) } \\
\text { (NCBI) }\end{array}$ & $\begin{array}{l}\text { GII.n/GQ856469 } \\
\text { GII/AB112321 }\end{array}$ & Negative & NP & NP \\
\hline $157 / 2003$ & $\begin{array}{l}\text { (RIVM) } \\
\text { (NCBI) }\end{array}$ & $\begin{array}{l}\text { GII.4/DQ078814 } \\
\text { GII.4/AY587988 }\end{array}$ & Negative & Negative & Negative \\
\hline $229 / 2003$ & $\begin{array}{l}\text { (RIVM) } \\
(\mathrm{NCBI})\end{array}$ & $\begin{array}{l}\text { GII.b/AY682549 } \\
\text { GII/AB231355 }\end{array}$ & Negative & $\begin{array}{l}\text { GII.3/EU187437 } \\
\text { GII.3/EU249137 }\end{array}$ & $\begin{array}{l}\text { GII.3/EU187437 } \\
\text { GII.3/GU292848 }\end{array}$ \\
\hline $230 / 2003$ & $\begin{array}{l}\text { (RIVM) } \\
\text { (NCBI) }\end{array}$ & $\begin{array}{l}\text { GII.4/DQ078814 } \\
\text { GII.4/EU310927 }\end{array}$ & Negative & $\mathrm{NP}$ & $\mathrm{NP}$ \\
\hline $239 / 2003$ & $\begin{array}{l}\text { (RIVM) } \\
\text { (NCBI) }\end{array}$ & $\begin{array}{l}\text { GII.4/DQ078814 } \\
\text { GII.4/EU310927 }\end{array}$ & $\begin{array}{l}\text { Bristol/X76716 } \\
\text { Lordsdale/X86557 }\end{array}$ & Negative & Negative \\
\hline $309 / 2003$ & $\begin{array}{l}\text { (RIVM) } \\
\text { (NCBI) }\end{array}$ & $\begin{array}{l}\text { GII.4/EU310927 } \\
\text { GII/DQ138986 }\end{array}$ & $\begin{array}{c}\text { Bristol/X76716 } \\
\text { Lordsdale/X86557 }\end{array}$ & $\begin{array}{l}\text { GII.4/DQ364459 } \\
\text { GII.4/EU310927 }\end{array}$ & $\begin{array}{l}\text { GII.4/DQ364459 } \\
\text { GII.4/DQ364459 }\end{array}$ \\
\hline 2/Ballsh/2010 & $\begin{array}{l}\text { (RIVM) } \\
\text { (NCBI) }\end{array}$ & NP & Negative & $\begin{array}{l}\text { GII.4/NA/GU445325 } \\
\text { GII.4/GU445325 }\end{array}$ & NP \\
\hline 4/Ballsh/2010 & $\begin{array}{l}\text { (RIVM) } \\
\text { (NCBI) }\end{array}$ & NP & $\begin{array}{l}\text { Bristol/X76716 } \\
\text { Lordsdale/X86557 }\end{array}$ & $\begin{array}{c}\text { GII.4/var2010/OB2009166 } \\
\text { GII.4/GU445325 }\end{array}$ & NP \\
\hline 14/Ballsh/2010 & $\begin{array}{l}\text { (RIVM) } \\
\text { (NCBI) }\end{array}$ & NP & $\begin{array}{c}\text { GII.4/var2010/OB2009166 } \\
\text { GII.4/HM625866 }\end{array}$ & $\begin{array}{l}\text { GII.4/NA/GU445325 } \\
\text { GII.4/GU445325 }\end{array}$ & NP \\
\hline 16/Ballsh/2010 & $\begin{array}{l}\text { (RIVM) } \\
\text { (NCBI) }\end{array}$ & NP & $\begin{array}{c}\text { GII.4/var2010/OB2009166 } \\
\text { GII.4/HM625866 }\end{array}$ & $\begin{array}{l}\text { GII.4/NA/GU445325 } \\
\text { GII.4/GU445325 }\end{array}$ & NP \\
\hline 18/Ballsh/2010 & $\begin{array}{l}\text { (RIVM) } \\
\text { (NCBI) }\end{array}$ & NP & $\begin{array}{c}\text { GII.4/var2010/OB2009166 } \\
\text { GII.4/HM625866 }\end{array}$ & $\begin{array}{l}\text { GII.4/NA/GU445325 } \\
\text { GII.4/GU445325 }\end{array}$ & Negative \\
\hline 21/Ballsh/2010 & $\begin{array}{l}\text { (RIVM) } \\
\text { (NCBI) }\end{array}$ & NP & Negative & $\begin{array}{l}\text { GII.4/GU445325 } \\
\text { GII.4/GU445325 }\end{array}$ & NP \\
\hline 26/Ballsh/2010 & $\begin{array}{l}\text { (RIVM) } \\
\text { (NCBI) }\end{array}$ & NP & $\begin{array}{l}\text { GII.4/var2010/OB2009166 } \\
\text { GII.4/HM625866 }\end{array}$ & $\begin{array}{l}\text { GII.4/NA/GU445325 } \\
\text { GII.4/JN595867 }\end{array}$ & $\begin{array}{c}\text { GII.4/var2010/OB2009166 } \\
\text { GII.4/HM596589 }\end{array}$ \\
\hline 27/Ballsh/2010 & $\begin{array}{l}\text { (RIVM) } \\
\text { (NCBI) }\end{array}$ & NP & Negative & $\begin{array}{l}\text { GII.4/NA/GU445325 } \\
\text { GII.4/GU445325 }\end{array}$ & $\begin{array}{l}\text { GII.4/NA/GU445325 } \\
\text { GII.4/HM596589 }\end{array}$ \\
\hline 30/Ballsh/2010 & $\begin{array}{l}\text { (RIVM) } \\
\text { (NCBI) }\end{array}$ & NP & $\begin{array}{l}\text { Bristol/X76716 } \\
\text { Lordsdale/X86557 }\end{array}$ & $\begin{array}{l}\text { GII.4/NA/GU445325 } \\
\text { GII.4/GU445325 }\end{array}$ & NP \\
\hline 32/Ballsh/2010 & $\begin{array}{l}\text { (RIVM) } \\
\text { (NCBI) }\end{array}$ & NP & $\begin{array}{c}\text { Bristol/X76716 } \\
\text { Lordsdale/X86557 }\end{array}$ & $\begin{array}{l}\text { GII.4/NA/GU445325 } \\
\text { GII.4/GU445325 }\end{array}$ & $\begin{array}{l}\text { GII.4/NA/GU445325 } \\
\text { GII.4/HM596589 }\end{array}$ \\
\hline
\end{tabular}

Negative, no amplicon; NP, Not performed; NA, variant not assigned by the database.

three as GII.n and one strain as GII.b (Table I). Using IIF/IIR/IIR2 primers, a proper amplicon has been obtained in 3 out of 11 positive stool samples that were clustered with Bristol/Lordsdale genotype (Fig. 1B). The genetic analysis of ORF2 (regions C and D) was carried out from eight GII positive specimens because, in three cases, it was not possible to perform the amplification for lack of sample. The genotyping has identified GII.3 and GII.4 strains, in both capsid regions, for the samples 229/2003 and 309/ 2003 , respectively. Samples 11/2002 and 14/2002 have shown a genotype non-concordant in capsid regions and they were identified between GII.3 and/or GII.2 genotype (Table I).

\section{Characterization of the Outbreak in Ballsh}

During the outbreak event, NoV was detected by amplification of $344 \mathrm{bp}$ size of the ORF1/ORF2 genome (region C) [Kojima et al., 2002; Kageyama et al., 2003]. Based on the NCBI data bank, all of the NoV GII strains detected were genotyped as GII.4 with a sequence homology of $98 \%$ with New Orleans2009 strain (accession number: GU445325) [Donia et al., 2011]. Only one isolate (26/Ballsh) showed $99 \%$ homology with the New Orleans-2010 variant strain (accession number: JN595867; Table I). According to the RIVM website, the 4/Ballsh isolate was assigned clearly to the GII.4 variant 2010 while the other GII.4 strains were classified as GU445325 strain, representing the variant New Orleans 2009 (Table I). The amplification of $250 \mathrm{bp}$ size of ORF-1gene (region A) carried out using IIF/IIR/IIR2 primers has produced a specific amplicon in 7 out of 10 positive samples. The homology analysis of the sequences has confirmed the GII.4 genotype but the strains of the outbreak were divided into two clusters (Fig. 1B), three strains 
A

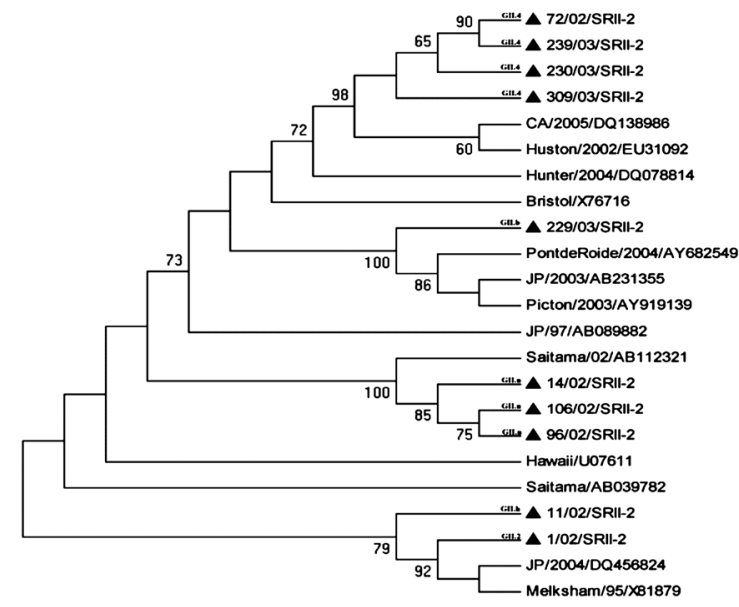

C

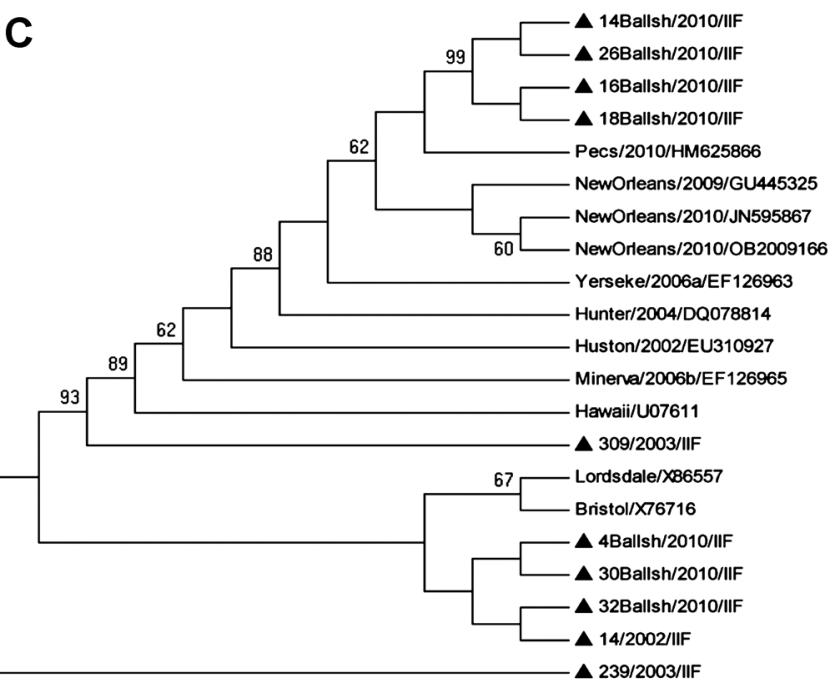

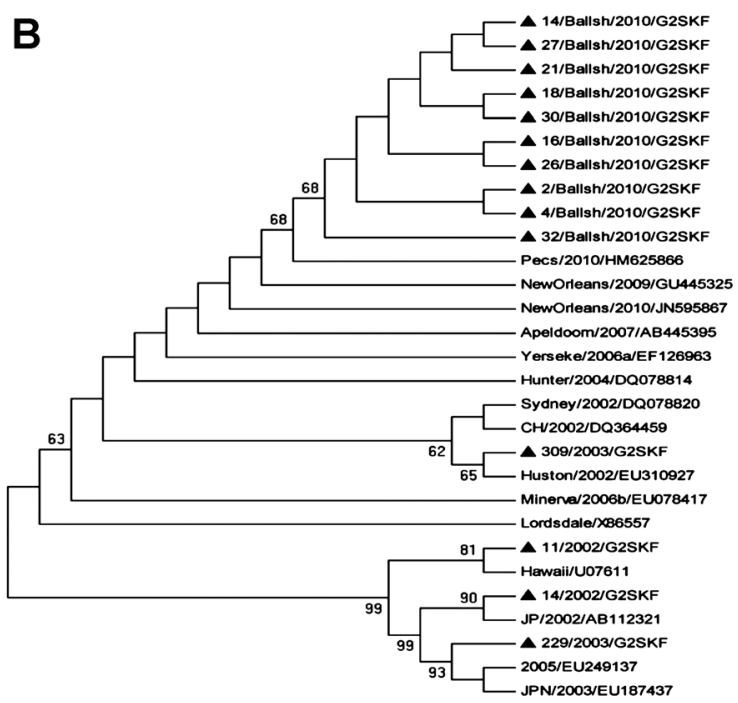

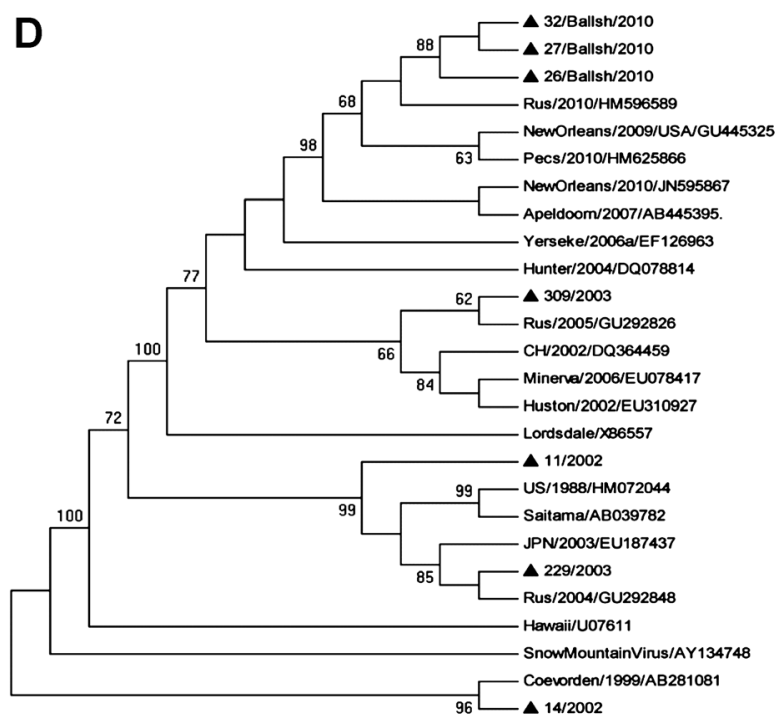

the neighbor-joining method and evaluated by using the interior branch test method with Mega 5.05 software (www.megasoftware. net). Percentage of bootstrap support is shown by values at the branch nodes of the trees. Only nodes with a bootstrap value $>60 \%$ are labeled; these values are the result of re-sampling the data 1,000 times.

BLAST program, all of the three strains have been assigned to the GII.4 Russian variant 2010 (97\% homology-accession number: HM596589). By RIVM website the GII.4 variant 2010 was confirmed clearly in one case (26/Ballsh), the other two GII.4 strains were classified as GU445325 genotype (Table I).

\section{DISCUSSION}

Presented data refer the first molecular characterization of NoV strains detected in Albania during two time periods: years 2002-2003 and 2010.

NoV GII strains detected in 2002-2003 were characterized amplifying three regions of the genome: region al. [2004]. Three samples have produced a prope amplicon for subsequent sequencing. Based on the 
A (ORF1), regions $\mathrm{C}$ and $\mathrm{D}$ (ORF2). In a first time the strains were classified by sequencing a tract of region A using SRII-2 primer. In a second time NoV GII strains were re-amplified and sequenced using IIF primer (region A), G2SKF primer (region C) and Cap $\mathrm{C}$ primer (region D).

Unfortunately, not all faecal samples have produced a proper amplicon after the new rounds of the amplification. The IIF/IIR/IIR2 primers have shown a low sensitivity (three out of eleven positive GII strains) that was clustered to the Brostol/Lordsdale genotype (Fig. 1C). Similar results were obtained by amplifying and sequencing the regions of capsid genome. Four proper amplicons were obtained and sequenced in both capsid regions (regions $\mathrm{C}$ and $\mathrm{D}$ ). The genotype was coincident in two cases, the strains 229/2003 and 309/2003, as GII.3 and GII.4, respectively. The genotyping of the capsid region (regions $\mathrm{C}$ and $\mathrm{D}$ ) was divergent considerably for the other two NoV GII strains, $11 / 2002$ and $14 / 2002$, which suggests the recombinant origin of the strains (Fig. 1B,D). Indeed, analyzing data obtained on the basis of the sequencing of the region $\mathrm{A}$, the strain 11/2002 was confirmed as recombinant strain (GII.h, accession number: AB089882) while the strain 14/2002 showed high homology with other NoV GII strain as reported by Ambert-Balay et al. [2005]. The same classification was observed for the strains 96/2002 and 106/2002 after the analysis of ORF1 sequences; for these strains it can be hypothesized the recombination event because not supported from the sequencing of the capsid regions (Table I). The strain 229/2003 showed a sequence homology in ORF1 related closely to GII.b recombinant strain (accession number: AY 682549 ), in ORF2 the homology was closely related to GII.3 strain as identified in France in August 2000 [Ambert-Balay et al., 2005]. Five strains were classified as NoV GII.4 (Table I) and the strain 309/2003 was sub-typed as NoV GII.4 variant Huston/2002 by RIVM website. Phylogenetic analysis of region A (SRII-2 primer) has clustered all strains between the Huston/2002 and Hunter/2004 (accession number: EU310927, DQ078814) demonstrating the circulation of these pandemic variants in Albania since 20022003 (Fig. 1A). Unfortunately, we have not information about any outbreaks relatively to the time period analyzed.

Genotyping of the outbreak strains was completed amplifying a portion of the three regions of the genome. The common origin of the outbreak was defined because of all the isolates were found to belong to GII.4 genotype (Fig. 1C). However, slight variations were observed comparing the sequence homology of the region $\mathrm{A}$ among data banks. GII.4 sub-type variant 2010 was straightaway assigned to $4 /$ Ballsh by RIVM and to $26 /$ Ballsh by BLAST websites. The primers used to amplify this region (IIF/IIR/IIR2) revealed a good sensitivity and specificity in detection and genotyping (70\%) but a little less effectiveness in sub-typing (57\% of sequences were assigned to a GII.4 variant). Indeed, the phylogenetic analysis has divided the strains in two clusters for few amino acid differences (Fig. 1B). In particular, substitutions were observed in the amplicon at the position $2, \mathrm{M}>\mathrm{V}$, position $8, \mathrm{~K}>\mathrm{T}$, position $48, \mathrm{I}>\mathrm{T}$ (in four strains) respect to the Lordsdale cluster; two other substitution were observed in all of the strains at position 69 , $\mathrm{N}>\mathrm{K}$, position $71, \mathrm{~N}>\mathrm{D}$, respect to the GII.4 New Orleans variant 2010. Many amino acid substitutions have been identified in the central region of RdRp, as reported in the literature [Kojima et al., 2002]. This primers have demonstrated to produce a specific amplicon after a single round of PCR (70\%) reducing the detection times (data not shown). This last result disagrees with Kojima et al. [2002] that report a lower detection capability of primers to target the central region of RdRp, after the first step of PCR (31\%), in a broader range of NoV GII strains. The sequence analysis of VP1 region D of the genome has been obtained from three samples. The outbreak strain was assigned, by sequence homology analysis, to the GII.4 variant 2010, considered the pandemic variant responsible of the epidemic events that occurred worldwide during 2009-2010 [Mathijs et al., 2011; Vega et al., 2011]. Over the last decade five NoV pandemic events have been reported associated with the genotype GII.4 and each of them have been trigged from a mutated strain [Blanton et al., 2006; Bull et al., 2006; $\mathrm{Tu}$ et al., 2008; Siebenga et al., 2009]. In the absence of a reliable cell culture system, the RT-PCR is considered the gold standard for NoV detection. A large selection of primers are available currently and these are able to amplify the most of genetic variants arising from the accumulation of point mutations associated with genetic recombination events. Most of the investigators have chosen primers for conserved regions, such the RdRp gene, in order to detect the greatest number of different strains [Jiang et al., 1990, 1993; Ando et al., 2000; Katayama et al., 2002; Vinjé et al., 2004] but not all sequences can be accurately classified into the proper clusters by phylogenetic analyses [Zheng et al., 2006]; however, GII.4 variants were observed after the molecular analysis of the ORF1 region [Marshall and Bruggink, 2011]. During the last years it highlights a lack of reported data about sequence analyses of RdRp region that could suggest the use of this approach in addition to the VP1 capsid protein study chosen by the major networks of NoV surveillance [Park et al., 2011].

The recombination events in the $\mathrm{NoV}$ have been demonstrated as a common feature reported likely in other RNA virus [Bull et al., 2007]. During 2006, the NoV GIIb/GII.3 recombinant was the most prevalent NoV strain involved in outbreaks and investigated in Queensland, Australia [Tu et al., 2008]. A similar recombinant strain was identified in France since 2000 as reported by Ambert-Balay et al. [2005]. In this study, six NoV GII strains have been characterized as GII recombinant strains, all of them among those detected during 2002-2003. 
The molecular characterization is an important tool to better understand the genetic variability of NoVs. The New Orleans GII.4 variant was first identified in October 2009 causing $60 \%$ of the outbreaks worldwide, replacing the predominant GII.4 Minerva strain. As expected, the rapid global spread of emerging GII.4 variants during the last 10 years has involved also the Albania. Data reported in this study reflect the contemporary presence in Albania of NoVs strains circulating in Europe during the years considered.

\section{REFERENCES}

Ambert-Balay K, Bon F, Le Guyader F, Pothier P, Kohli E. 2005. Characterization of new recombinant noroviruses. J Clin Microbiol 43:5179-5186.

Ando T, Noel JS, Fankhauser RL. 2000. Genetic classification of Norwalk-like viruses. J Infect Dis 181:S336-S348.

Arrivi F, Donia D, Gabrieli R, Petrinca AR, Cenko F, Bebeci D, Doro Altan AM, Buonomo E, Divizia M. 2007. The influence of enteric viruses on gastroenteritis in Albania: Epidemiological and molecular analysis. J Med Virol 79:1844-1849.

Belliot G, Sosnovtsev SV, Mitra T, Hammer C, Garfield M, Green KY. 2003. In vitro proteolytic processing of the MD145 norovirus ORF1 nonstructural polyprotein yields stable precursors and products similar to those detected in calicivirus-infected cells. J Virol 77:10957-10974.

Blanton LH, Adams SM, Beard RS, Wei G, Bulens SN, Widdwson MA, Glass RI, Monroe SS. 2006. Molecular and epidemiologic trends of caliciviruses associated with outbreaks of acute gastroenteritis in the United States 2000-2004. J Infect Dis 193:413-421.

Bull RA, Tu ET, McIver CJ, Rawlinson WD, White PA. 2006. Emergence of a new norovirus genotype II.4 variant associated with global outbreaks of gastroenteritis. J Clin Microbiol 44:327-333.

Bull RA, Tanaka MM, White PA. 2007. Norovirus recombination. J Gen Virol 88:3347-3359.

Corpet F. 1988. Multiple sequence alignment with hierarchical clustering. Nucleic Acids Res 16:10881-10890.

Donia D, Kota M, Leno L, Ylli A, Cenko F, Divizia M. 2011. First outbreak of norovirus in Albania. Lett Appl Microb 53:283287.

Eden JS, Bull RA, Tu E, McIver CJ, Lyon MJ, Marshall JA, Smith DW, Musto J, Rawlinson WD, White PA. 2010. Norovirus GII.4 variant $2006 \mathrm{~b}$ caused epidemics of acute gastroenteritis in Australia during 2007 and 2008. J Clin Virol 49:265-271.

Häfliger D, Gilgen M, Lüthy J, Hübner P. 1997. Seminested RTPCR systems for small round structured viruses and detection of enteric viruses in seafood. Int J Food Microbiol 37:27-36.

Hedberg CW, Osterholm MT. 1993. Outbreaks of food-borne and waterborne viral gastroenteritis. Clin Microbiol Rev 6:199-210.

Kageyama T, Kojima S, Shinohara M, Uchida K, Fukushi S, Hoshino FB, et al. 2003. Broadly reactive and highly sensitive assay for norwalk-like viruses based on real-time quantitative reverse transcription-PCR. J Clin Microbiol 41:1548-1557.
Katayama K, Horikoshi HS, Kojima S, Kageyama T, Oka T, Hoshino FB, Fukushi S, Shinohara M, Uchida K, Suzuki Y, Gojobori T, Takeda N. 2002. Phylogenetic analysis of the complete genome of 18 norwalk-like viruses. Virology 299:225-239.

Kojima S, Kageyama T, Fukushi S, Hoshino FB, Shinohara M, Uchida K, Natori K, Takeda N, Katayama K. 2002. Genogroupspecific PCR primers for detection of Norwalk-like viruses. J Virol Methods 100:107-114.

Koopmans M, von Bonsdorff CH, Vinjé J, De Medici D, Monroe S. 2002. Foodborne viruses. FEMS 26:187-205.

Jiang X, Graham DY, Wang K, Estes MK. 1990. Norwalk virus genome cloning and characterization. Science 250:1580-1583.

Jiang X, Wang M, Wang K, Estes MK. 1993. Sequence and genomic organization of Norwalk virus. Virology 195:51-61.

Marshall JA, Bruggink LD. 2011. The dynamics of norovirus outbreak epidemics: Recent insights. Int $J$ Environ Res Public Health 8:1141-1149.

Mathijs E, Denayer S, Palmeira L, Botteldoorn N, Scipioni A, Vanderplasschen A, Thiry E, Dierick K. 2011. Novel norovirus recombinants and of GII.4 sub-lineages associated with outbreaks between 2006 and 2010 in Belgium. Virol J 8:310.

Park JW, Lee SG, Lee YM, Jheong WH, Ryu S, Paik SY. 2011. Full sequence analysis and characterization of the South Korean Norovirus GII-4 variant CUK-3. Virol J 8:167.

Patel MM, Widdowson MA, Glass RI, Akazawa K, Vinjé J, Parashar UD. 2008. Systematic literature review of role of noroviruses in sporadic gastroenteritis. Emerg Infect Dis 14:12241231.

Siebenga JJ, Vennema H, Zheng DP, Vinje J, Lee BE, Pang XL, Ho ECM, Lim W, Choudekar A, Broor S, Halperin T, Rasool NBG, Hewitt J, Greening GE, Jin M, Duan ZJ, Lucero Y, O'Ryan M, Hoehne M, Schreier E, Ratcliff RM, White PA, Iritani N, Reuter G, Koopmans M. 2009. Norovirus illness is a global problem: Emergence and spread of Norovirus GII.4 variants 2001-2007. J Infect Dis 200:802-812.

Siebenga JJ, Lemey P, Kosakovsky Pond SL, Rambaut A, Vennema H, Koopmans M. 2010. Phylodynamic reconstruction reveals norovirus GII.4 epidemic expansions and their molecular determinants. PLoS Pathog 6:e1000884.

Tamura K, Peterson D, Peterson N, Stecher G, Nei M, Kumar S. 2011. MEG A5: Molecular evolutionary genetics analysis using maximum likelihood, evolutionary distance, and maximum parsimony methods. Mol Biol Evol 28:2731-2739.

Tu ET, Bull RA, Greening GE, Hewitt J, Lyon MJ, Marshall JA, McIver CJ, Rawlinson WD, White PA. 2008. Epidemics of gastroenteritis during 2006 were associated with the spread of norovirus GII.4 variants 2006a and 2006b Clin Infect Dis 46:413-420.

Vega E, Barclay L, Gregoricus N, Williams K, Lee D, Vinjé J. 2011. Novel surveillance network for norovirus gastroenteritis outbreaks, United States. Emerg Infect Dis 17:1389-1395.

Vinjé J, Hamidjaja RA, Sobsey MD. 2004. Development and application of a capsid VP1 (region D) based reverse transcription PCR assay for genotyping of genogroup I and II noroviruses. J Virol Methods 116:109-117.

Zheng DP, Ando T, Fankhauser RL, Beard RS, Glass RI, Monroe SS. 2006. Norovirus classification and proposed strain nomenclature. Virology 346:312-323. 